\title{
The Challenges of Working and Studying at a Satellite Campus of a University: A Case of the Durban University of Technology
}

\author{
Dr D. C. Hlengwa \\ Department of Ecotourism, Durban University of Technology, Durban, South Africa \\ dumisileh@dut.ac.za
}

Doi:10.5901/mjss.2014.v5n27p661

\begin{abstract}
Universities seem to be facing a turbulent storm of challenges in the midst of economic meltdown and growing access demands. The environments in which they operate are becoming increasingly competitive making sound leadership crucial. Changes and institutional mergers that took place worldwide two decades ago diffused to the south of Africa as well resulting in the formation of mega universities. This study was conducted in order to establish the challenges that staff and students at satellite campuses face using the case of the Riverside Campus of DUT. Literature on leadership and management theories, and organisational structures was reviewed in order to contextualise the study. A sample of the executive leadership of the university was interviewed and data was also gathered from academic and administrative staff as well as first and third year students at the satellite campus using questionnaires. The study discovered that there were still leadership challenges which were not unique to the university and campus, but similar to those identified during literature review. Issues such as lack of leadership and strategic direction, diverse cultures, incomplete merger, isolation, inequitable distribution of resources, etc. were identified as challenges that needed to be addressed. At its best leadership is proximate, contextual and distributed especially in the case of complex organisations. The study advances as original contribution the 'Radial Structure', which was inspired by the natural distribution of energy in fractals. This structure ensures equitable distribution of resources across all campuses irrespective of size and location.
\end{abstract}

Keywords: Radial structure, Organisational structure, Prototype, Satellite campus, Leadership,

\section{Introduction}

This study is significant because it feeds into the year-long study initiated by the Leadership Foundation on Higher Education and conducted between 2010 and 2011 by the Hull University's Scarborough Campus that was aimed at determining the most effective relationship between the main campus and its satellite campuses, identifying tensions between the strategic and operational levels and making student experience consistent. The participants all agreed that the key indicators of leadership model effectiveness included among others the presence of the Deputy Vice Chancellor (DVC) at the satellite campus, a relevant proportion of resident professors, seniority and academic leadership, regular travel and communication arrangement for teaching and research and other purposes (Reisz, 2011:1).

\section{Literature Review}

The higher education (HE) is characterised by change fuelled by macro environmental factors which universities have no control over such as politics, economy, technology, etc. Change currents in one of the elements reverberate across all the elements and positively or negatively impact on all organisations. Close \& Raynor (2010:217) postulate that organisations are living within shifting sands of interdependence where they experience themselves paradoxically as free and constrained at the same time because they are individual institutions that are not independent of the environment in which they operate. Change is the order of the day that is not only desirable, but also inevitable and leaders therefore have to create the culture of change as they try to develop a better fit between the institutions and the unique needs of their dynamic environments (Serfontein, 2010:3; Cloud, 2010:74; Viljoen \& Rothmann, 2002:1). Middlehurst (2010:75); Scott et al (2010:401) vouch that universities worldwide have entered a turnaround point of disquieting turmoil that has no end in sight. Stringer \& Hudson (2008:1); Skodvin (1999:65) consider the changes in the HE sector to have been fuelled by government reform as well as socio-economic and technological advancements aimed at efficiency, while Kezar et al (2011:129) are concerned about the capacity of the institutions to cope and adapt as change initiatives mount throwing institutions which are already complex into further turmoil. Cloete et al (2002:13) concur with this fact when they point out 
that social transformation in South Africa was part of a political and economic transition process on a planetary scale.

The HE sector of any country is in actual fact one of the drivers of change through discovery of new knowledge and experimentation of how the new knowledge has to be used for the benefit of society. On this note Billing (1998:12) indicates that organisations find it easier to adapt to gradual changes, but get destabilized by dramatic changes which we have seen gripping HE. The newly formed mega universities necessitate new leadership styles and structures that are flexible and bring leadership to the people where it is most needed. Marshall (2007:1) advocates for dispersed forms of leadership that bring guidance to where the people are and help improve competitiveness through the tireless communication of institutional mission, goals and strategy. Power and decision-making in these leadership styles and architectures should be centralised, decentralised and re-centralised, and management should always be seen as change management in response to the ever changing environment.

\subsection{Rationale for Development of Satellite Campuses}

Satellite campuses came into being in order to cater for the growing demand of HE in areas removed from the mother university to deal with the issues of accessibility, demand overload, address decline in enrolment at the main campus, convenience and extension of reach for universities to markets that were previously out of reach as well as at the request of the region in question (OCUFA, 2009:5,12; Redmond, 2008; Bianchi, 2000:261; Teferra \& Altbach, 2004:21). Reisz (2010) emphasises the importance of increasing confidence and maintaining such campuses to provide sustainable quality $\mathrm{HE}$ in remote areas.

Hacker \& Dreifus (2010:2) talk about universities establishing branches abroad in order to be distinctive, have prestige, make imprints, and because they are tired of operating in the same place, grow graduate and research output and diversify income, which adds a complication of managing a (Bambrick, 2002:2) distributed university. In Michigan the development of satellite campuses was also aimed at providing access opportunities especially to rural parts as the government had realised that it was becoming increasingly viable to invest in the workforce for sustainable economic prosperity (Cunningham et al, 2008:5). In South Africa the formation of multi-campus universities was in alignment with what Cloete, et al (2002:13), call the 'new world order' of globalization, political and socio-economic changes of the 1990s. To keep abreast of the global developments the SA government advocated for the changes in HE aimed at restructuring this sector to address the inequalities that existed prior to the democratic dispensation.

\subsection{Challenges Associated with Multi-campus Universities}

Universities with satellite campuses are still faced with a number of complexity challenges that are pedagogical, managerial, economic, and logistical in nature (Ebden, 2010:267), demanding unprecedented kind of leadership and administration. Stringer \& Hudson (2008) suggest that the best form of leadership to deal with these challenges is distributive, cooperative, and deliberate aimed at achieving semblance of standards and equivalence of experience while supporting differing cultural and geographical needs across campuses especially those located in other cities or provinces.

\subsubsection{Leadership Challenges}

When Laurier Brantford Campus of Wilfrid Laurier University started to operate in 1999, it had only 40 full-time students and 3 full-time staff. Despite these alarmingly small figures a dean and a campus manager (CM) were appointed to represent the campus at senate and other governing bodies of the university as well as with local outside stakeholders (OCUFA, 2009:7, 8). Allison \& Eversole (2008:100) confirm that most regional campus models in Australia involved the adoption of a $\mathrm{CM}$ or pro-vice chancellor (PVC) whose mandate is seeing to all the campus activities, driving implementation of the university strategy, ensuring that the campus meets the regional needs and responds to local pressures. In all the management structures they suggested for Grenfell College of Memorial University, Davis \& Kelly (2006:7) emphasise the importance of the presence of a senior person such as DVCs in each of the two campuses, both reporting directly to the vice chancellor.

Ajadi (2009:579) states that all the study centres of the National Open University of Nigeria (Noun) were headed by CMs tasked with the responsibility to perform some functions of the headquarters even though there was no face-to-face teaching and learning taking place. A study conducted on satellite programmes of Nigerian universities discovered that there was limited monitoring of the campuses and programmes, and the researcher expressed need to apply stringent monitoring procedures to ensure alignment the main campus (Ali, 1996:1). In an attempt to strengthen the university 
brand and ensure commonality of purpose, the Southern Cross University (Australia) responded to the audit report by appointing a PVC at its Coffs Harbour Campus and relocating some staff members to strengthen the academic profile at this campus (Hilary et al, 2006:5). Singh \& Khanna (2011:2) on branch campus development raise concerns that it would not be easy to maintain similar quality and standards with the main campus at such campuses as the university would need to send the faculty to the branch while it is also needed at home.

Hatton (2002:5) observes that the decentralised integrated model had led to such interwovenness that disamalgamation would be unthinkable at Charles Stuart University. CSU was commended by Hilary et al (2006:4) for one university culture across all its campuses, strong support for staff, visibility of VC and other senior executives who maintained a high profile across all locations. Leadership at all the levels allows the institution to maintain the common standards of service delivery while keeping the eyes on the horizon, anticipating change and gearing itself up to meet the challenges and even lead and drive sectorial change (Joyce, 2010:292). Allison \& Eversole (2008:99) state that satellite campuses tend to be second choice for both staff and students and that the staff at satellite campuses tend to feel dislocated and operate 'without the underlying rubric' of the top management, while Timberlake (2004:94) worries about loss of identity and disconnection from the rest of the university. Mathebula \& de Beer (2010:1) further suggest that even though there could be characteristic differences between the main campus and its satellite campuses, their management infra-structure should maintain common features with those of the main campus.

In a leadership study conducted by the Griffith University on managing multi-campus challenges, Krause et al (2010:1) uncovered challenges such as: managing consistency and equivalence across campuses, policy issues that reflect multi-campus specific needs, cross-campus communication that enhances a sense of belonging to the bigger university, curriculum quality and standards and semblance of support services and facilities. In some universities of South Africa the formation of new management structures, location and distribution of resources, leading bigger and dispersed universities, and location of faculties across campuses were still thorny issues (de la Rey, 2009:8).

\subsubsection{Service Delivery Challenges}

Hilary et al $(2006: 3,4)$ comment on the lack of inclusive and consistent culture across all the satellite campuses of La Trobe University, low staff profile and limited professorial presence at the University of Newcastle's satellite campus Ourimbah. Such conditions render the campuses not fit for purpose especially because there is no embodiment of such purpose on campus. One of the challenges of multi-campus universities developed through a merger as identified by Hall et al (2004:126) is that it is difficult for the merged universities to forgo their different cultures. De la Rey (2010:9) points out that even though similar identities have been developed for some merged institutions: such as one council, logo, vision and mission, there were still underlying cultural, racial, infrastructural, and other disparities. There is quite a number research articles that have been published on the outcomes of the transformation of HE in South Africa. The focus should now be on governance, leadership and management for efficiency, effectiveness and consistency across the whole university. Kamsteeg (2008) identifies a need to conduct a study across all the campuses of the merged NorthWest University because of the feeling that there were still numerous unresolved merger issues such as a sense of one university and cohesion.

Multi-campus universities need to address the challenges of maintaining consistency across the whole university otherwise the satellite campuses remain (Ezarik, 2009) less attractive to the staff and students as they do not offer as wide a range of facilities, courses and opportunities as the main campus. Liu \& Lv (2007) caution that universities with satellite campuses may find it difficult to allocate the resources equitably across the dispersed campuses. Hilary et al $(2006: 1,5)$ observe that satellite campuses are apt to be remote, marginalised, forgotten, exploited, characterised by fragmentation, duplication, inconsistency and inequitability. They hold that such issues can be addressed through robust and effective planning, leadership, quality management systems, efficient communication and equitable resource distribution. Mathebula \& de Beer (2003:3) discovered that the main campus faculties tend to downrate and disrespect the staff and academic activities at satellite campuses, while Gaskell (2011:1); Allison \& Eversole (2008:98) observed that the satellite campuses are usually vulnerable in times of university turbulence and cost cutting strategies and display a lower status to that of the metropolitan campus.

\section{Methodology}

The approach used in this study is that reality is created by the people that experience the situation. Consequently the study takes seriously the meaning that the people attribute to their situation in naturally occurring settings (Bell, 2010:14), which in this case is working and studying at a satellite campus of a university using both qualitative and quantitative 
paradigms. The Riverside Campus of DUT is used as a case for investigation and description to enable the researcher to compare experiences at this campus with the experiences at other satellite campuses worldwide, as the literature review laid bare. This phenomenological approach allows for an intensive investigation of the complexities of the phenomenon of concern using a single bounded system (Maree \& van der Westhuizen, 2009:21). This approach is appropriate since the study was designed to develop theory and not to generalize it (Marschan-Piekkari \& Welch, 2004:105, 109). This study is an empirical enquiry aimed at investigating a (Soy, 2006:1; Glesne, 2006:13) contemporary phenomenon within its reallife context thus leading to a more holistic report. The study was cross-sectional conducted between March 2012 and May 2013 and so it provides snapshot data of the conditions as they prevailed at the time of study.

\subsection{Target Population and Sampling}

The groups of individuals that share the most common characteristics and attributes to which the research questions refer and who were potentially available as respondents in this study were the executive leadership of DUT, the deans of the Faculties of Management Sciences and Accounting \& Informatics, academic and administrative staff, and first and thirdyear students across all programmes offered at the Riverside Campus. The study had a target population of 1133 people as indicated.

\subsection{Sample Selection}

As table 1 illustrates, the population is composed of various sub-populations made of the executive leadership, academic and administrative staff, and the first and third-year students.

Table 1: The sub-populations of study

\begin{tabular}{|c|c|c|c|c|c|c|}
\hline Executive Leadership & $\begin{array}{l}\text { Deans of } \\
\text { Faculties }\end{array}$ & $\begin{array}{l}\text { Academic } \\
\text { staff }\end{array}$ & $\begin{array}{c}\text { Administrative } \\
\text { staff }\end{array}$ & \multicolumn{2}{|r|}{ Students across all 8 programmes } & \multirow[t]{2}{*}{ Total } \\
\hline & & & & $3^{\text {rd }}$ year & $1^{\text {st }}$ year & \\
\hline 19 & 2 & 30 & 26 & 385 & 668 & 1133 \\
\hline \multicolumn{7}{|c|}{ Sample Sizes } \\
\hline \multicolumn{2}{|l|}{ Interviews } & \multicolumn{4}{|c|}{ Questionnaires } & \\
\hline $25 \%$ & $100 \%$ & $100 \%$ & $100 \%$ & $25 \%$ & $25 \%$ & \\
\hline 4 & 2 & $40 \%$ & $69 \%$ & 96 & 167 & \\
\hline $\begin{array}{c}2 \text { were interviewed (the } \\
\text { other } 2 \text { were not } \\
\text { available) }\end{array}$ & $\begin{array}{c}\text { Both } \\
\text { interviewed }\end{array}$ & 12 & 20 & & $\begin{array}{l}220 \text { Sampling error (more respondents than } \\
\text { sampled as more first year students wanted to } \\
\text { complete the questionnaire) }\end{array}$ & 362 \\
\hline
\end{tabular}

The researcher used both probability and non-probability sampling techniques (Maree, 2012:77) because of the various sub-populations from which the samples had to be drawn. The executive leadership and staff form relatively small subpopulations. The researcher therefore used purposeful and census approaches (Blumberg et al, 2008:171) to data collection in these cases. A table of random numbers was generated and used to select a sample from the student subpopulations.

\subsection{Data Collection Methods}

The researcher interviewed the executive leadership of the university (VC and one DVC) including the two deans whose faculties are represented at the Riverside Campus. The lecturers, support staff, and the student populations were given questionnaires. One questionnaire was used to gather both qualitative and quantitative data. The researcher triangulated data collection and analysis in order to answer research questions and address the research objectives (Pieterse and Sonnekus, 2003). It was important to select sizable samples especially from the student population and quantify their responses for the validity of the research findings. The data collection techniques chosen provide the study with the scientific and statistical information regarding the sufficiency of data collected. It also provides plausibility and rich descriptive and analytical accounts of the situation under investigation (Cousin, 2009:8).

\subsection{Data Analysis and Interpretation}

The questionnaires were developed to include qualitative as well as quantitative items. Data analysis and interpretation 
techniques, therefore, followed data collection techniques. A statistician was used to capture data and develop statistical tools such as tables, graphs and other data representation tools as discussed with the researcher. It was important to capture and document the meanings attached to the situation and experiences of the participants using themes. The results were then linked to the research problem, research objectives.

\section{Findings}

The responses of the participants reflected their experiences. The regression model developed from the responses of the students is summarised in its linear form as follows:

Quality of Service $=0.758+(0.163 \times$ Administrative Service $)+(0.05 \times$ Library Facilities $)+(0.022 \times$ Condition of Classrooms $)+(0.185 \times$ Health Services $)+(0.103 \times \mathrm{SRC})$. The two significant (non-zero) predictors are Administrative Services and Health Services.

Table 2 displays the summary of the responses of all the participants measured against the research objectives which was done in order to compare the research findings to the objectives, draw the patterns and conclude the study. The issues that emerged from the analysis of data were growing student numbers on the midlands campuses of the university and then adjusting the organisational structure to include two principals for the two regions (Durban and Pietermaritzburg); need to appoint a strategic planner whose main function would be the creation of one university culture, interrogation of current structures and adjustments for better service delivery across the whole university; need for the satellite campuses to be fully-developed with resources that reflect those of the main campus and the need for the executive leadership to make their presence felt across all campuses though regular, scheduled and meaningful visits.

Table 2: Summary of all the responses in relation to research questions

\begin{abstract}
Executive Leadership Incomplete merger, two diverse cultures. Appointment of the CM, appointment of the strategic planner for the university, increase numbers at the midlands then appoint two regional principals. The collegial model headed by a DVC and deans devolved to campuses. No major challenges because the campuses are not too far.

Academic Staff

Poor culture, no strategic direction, strategic drift, isolation, less number of professors and doctors. Failure to attract the right calibre of students due to marketing campaigns directed to Durban. The name of the university is disadvantageous to midlands. Appointment of the CM to drive development.
\end{abstract}

\section{Research Objectives}

- What are the management, leadership, academic and administrative challenges faced by the staff and the students at satellite campuses of universities?

- To what extent does the absence of the executive leadership of the university on campus affect the academic culture?

- What mechanisms can be put in place to effectively represent satellite campuses at the executive level of the university?

- To what extent are the vision, mission, goals, and the overall direction of the university understood by the staff and students at satellite campuses?

- What is the management and leadership model that can be used (with some modifications) by universities with satellite campuses to improve leadership effectiveness and alignment with the main campus (contribution of the study)?

\author{
Administrative Staff \\ Takes time to get feedback from main \\ campus, demotivated staff, poor \\ understanding of the strategic direction, \\ discrepancies in infrastructural \\ provision. A fair understanding of the \\ vision of university. Appointment of the \\ CM to represent satellite campus at \\ executive level and improve campus \\ culture. More visibility for the campus. \\ Students \\ Poorly understood, complaints that it \\ changes all the time. Important to know \\ the leadership of the university for \\ reference and to have issues attended \\ to. Need for more programmes Satellite \\ campus to be fully developed and well- \\ equipped. Students satisfied with level \\ of service delivery even though \\ resources are minimal. The student \\ seemed to think that if administrative \\ and health services are increased and \\ improved, the overall quality of their \\ experience on campus would improve \\ as indicated in the regression model.
}




\section{The Radial Structure}

The radial structure advanced by the study is future-oriented and looks beyond the current staffing cohorts of the university into what could be. The term 'Radial' means radiate from and converge to a common centre (corporate division). In the radial structure (closely linked to the amorphous architecture) the corporate division is the source of energy in the form of vision, mission, goals, strategy, and resources which it disburses equitably across all the campuses. The corporate division is not attached to any campus, but it is a pole that provides an anchor for all the campuses. The energy in the form of student fees, leadership challenges and possible solutions, research output from staff and students, pass rates, information to aid decision-making, etc. is also radiated back to the corporate office from all the campuses.

The structure is advantageous in cases where the organisation still envisages further growth into other regions as it makes it easy to adapt to growth and change. Each campus would be strategically linked to the university but given enough autonomy to grow and shape itself according to the needs of the region in which it is embedded.

\section{Suggested Future Actions}

The study suggests that institutions stop relying on old organisational structures even if they fail to facilitate efficient service delivery. If the university wants to be embedded in the community that it serves, satellite campuses be allowed some autonomy within the master strategic plan of the university. The provision of student services should grow proportionately to the growth and development of the campus. There should be an executive office in each campus to allow the executive leadership to visit on schedule and make their presence felt. Efforts should be made to make the name of a university broader than the location of the main campus to avoid confusion.

\section{Conclusion}

The theories such as proximity, leadership within context, etc. build a strong case for leadership institution at all the campuses of the university. The study aimed at showing that the rationale for having many leaders within an institution should be that there is no leadership vacuum at any branch. The gaps identified by the study can be dealt with through the interrogation of the current governance and leadership structures and commitment to ensuring the semblance and maintenance of set standards across a distributed university.

\section{References}

Ajadi, T.O. 2009. Organisation and management of open and distance education in Nigeria: a case of National Open University of Nigeria (Noun) [Online]. European Journal of Scientific Research, Vol.38, No.4, 2009, 577-582. Available: http://www. eurojournals.com/ejsr.htm [Accessed: 24 October 2011].

Allison, J. \& Eversole, R. 2008. A new direction for regional university campuses: catalyzing innovation in place [Online]. Innovation: The European Journal of Science Social Research, Vol.21, No.2, June 2008. Available: http://www.informaworld.com [Accessed: 10 November 2011].

Ali, A. 1996. Academic standards of extension and satellite programmes of Nigerian universities: Management and control [Online] Available: www.col.org/forum/PCFpapers/ali2.pdf [Accessed: 16 August 2011].

Bambrick, S. 2002. The Satellite/Remote Campus: A Quality Experience for Australian First Year Students? USQ [Online]. Available: www.aucea.org.au/wp-content/uploads/biblio pdf [Accessed: 23 March 2011].

Bell, J. 2010. Doing Your Research Project: A guide for first-time researchers in education, health and social science. McGraw-Hill: Berkshire.

Bianchi, M. 2000. Multi-campus model and quality approach in the organisation of big universities. The case of university seats in Romagna [Online]. Sinergie Rapporti di Ricerca No.9 2000 Available: www2.sa.unibo.it [Accessed: 12 January 2011].

Billing, D. 1998. Quality management and organisational structure in Higher Education [Online]. Journal of Higher Education Policy \& Management, 1360080X, Nov 1998, Vol. 20, Issue 2. Available: http://www.ebscohost.com [Accessed: 10 November 2011].

Blumberg, B.; Cooper, D.R. \& Schindler, P.S. 2008. Business Research Methods. McGraw-Hill: London.

Cloete, N.; Fehnel, R.; Maassen, P.; Moja, T.; Perold, H. \& Gibbon, T. 2002. Transformation in Higher Education: Global Pressures and Local Realities in South Africa. Lansdowne: Juta \& Company (Pty) Ltd.

Close, P. \& Raynor, A. 2010. Five literatures of organisation: putting the context back into educational leadership [Online]. School Leadership and Management, Vol.30, No.3, July 2010, 209 - 224. Available: http://www.informaworld.com [Accessed: 28 October 2011].

Cloud, R.C. 2010. Epilogue: Change leadership and leadership development [Online]. New Directions for Community Colleges, No.149, Spring 2010. Available: www.interscience.wiley.com [Accessed: 11 November 2011]. 
Cousin, G. 2009. Researching Learning in Higher Education: An Introduction to Contemporary Methods and Approaches. Routledge Taylor \& Francis Group: New York.

Cunningham, A.F.; Erisman, W. \& Looney, S.M. 2008. Higher education in Michigan: Overcoming challenges to expand access [Online]. Institute for Higher Education Policy, March 2008. Available: www.ihep.org [Accessed: 24 April 2011].

Davis, J.L. \& Kelly, J. 2006. Report on Sir Wilfred Grenfell College Review. DoE Gov: Newfoundland and Labrador.

de la Rey, C. 2009. Council on Higher Education; Higher Education Monitor No. 8. The state of Higher Education in South Africa [Online]. Available: [Accessed: 8 May 2013]. Council

Ebden, M. 2010. We're on a steep learning curve: The benefits and challenges of multi-campus university course delivery. Research and Development in Higher Education: Reshaping Higher Education, 33 (pp. 267-277). Melbourne, 6-9 July, 2010 [Online]. Available: www.herdsa.org.au/wp-content/.../2010/.../HERDSA2010_Ebden_M.pdf [Accessed: 4 May 2013].

Ezarik, M. 2009. Multi-campus planning: Behind the scenes. How four institutions solved their branch campus scheduling and transportation challenges. University Business. Norwalk, Connecticut: Professional Media Group LLC [Online]. Available: http://universitybusiness.com/viewarticle.aspx?articleid=1381 [Accessed: 4 May 2013].

Gaskell, C. 2011. Understanding satellite campuses [Online]. Available: www.lfhe.ac.uk/research/smallproject [Accessed: 03 September 2011].

Glesne, C. 2006. Becoming Qualitative Researchers: An Introduction. Pearson Education Inc: Boston.

Hacker, A. \& Dreifus, C. 2010. The trouble with going global [Online]. Newsweek, 00289604, Vol.156, Issue 12, 20/9/2010. Available: http://web.ebscohost.com [Accessed: 24 October 2011].

Hall, M.; Symes, A. \& Luescher, T. 2004. The governance of merger in South African Higher Education: Research report prepared for the Council on Higher Education [Online]. Available: http://www.che.ac.za [Accessed: 8 May 2013].

Hatton, E.J. 2002. Charles Sturt University: A case of institutional amalgamation [online]. Higher Education 44. Kluwer Academic Publishing. Available: www.jstor.org/stable/3447550 [Accessed: 27 June 2011].

Hilary, P.M.; Winchester, W. \& Sterk, B.F. 2006. Multi-Campus University Management. Lessons from AUQA Audit Reports [Online]. Available: www.auqa.edu.au/../paper_a5.pdf [Accessed: 25 April 2011].

Joyce, P. 2010. Get your mojo working: complexity's call for magnetic and magical leaders [Online]. International Journal of Leadership in Education. Vol.13, No. 3, July - September 2010, 283 - 299. Available: http://www.tandf.co.uk/journals [Accessed: 10 November 2011].

Kamsteeg, F. 2008. In search of a merged identity: the case of multi-campus North-West University, South Africa. TD: 2008 Vol. 4 No.2 [Online]. Available: http://hdl.handle.net/10394/3939 [Accessed: 8 May 2013].

Kezar, J.; Gallant, T.B. \& Lester, J. 2011. Everyday people making a difference on college campuses: the tempered grassroots leadership tactics on faculty and staff [Online]. Studies in Higher Education. Vol. 36, No. 2, March 2011, p129 - 151. Available: http://www.informaworld.com [Accessed: 15 November 2011].

Krause, K.; Lizzio, A.; Bath, D.; Clark, J.; Scott, G.; Campbell, S.; Spencer, D. \& Fyffe, J. 2010. Effective program leadership: managing multi-campus challenges. [Online]. ALTC. Program Leader Project: Good Practice Guide. Available: www.griffith.edu.au/data/assets/pdf [Accessed: 08 September 2011].

Liu, X. \& Lv, X. 2007. Research on science and technology innovation of multi-campus universities in China [Online]. Available: http://snidely.dlib.vt.edu:8081/dspace/bitstream/2340/277/1/068Liu.pdf [Accessed: 4 May 2013].

Marschan-Piekkari, R. \& Welch, C. 2004. Handbook of Qualitative Research Methods for International Business. Edward Elgar: Cheltenham.

Maree, J.G.K. 2012. Complete you thesis or dissertation successfully: Practical guidelines. Juta: Cape Town.

Maree, K. \& van der Westhuizen, C. 2009. Head start in Designing Research Proposals in Social Sciences. Juta: Cape Town.

Marshall, S. 2007. Strategic Leadership of Change in Higher Education: What is new? Routledge Taylor \& Francis Group: London.

Mathebula, M.R. \& de Beer, K.J. 2003.In search of universal guidelines for the management of a satellite campus for higher education [Online]. Available: www.oerafrica.org pdf [Accessed: 10 August 2011].

Mathebula, M.R. \& de Beer, K.J. 2010. In search of universal guidelines for the management of a satellite campus for higher education [Online]. OER Africa: Saide. Available: http://preview4.bluematrix.co.za [Accessed: 13 October 2011.

Middlehurst, R. 2010. Sustaining leadership in challenging times [Online]. Higher Education Management and Policy, Vol.22/3. Available: www.oecd.org/documents [Accessed: 03 October 2011].

OCUFA. 2009. Policy Position on Satellite Campus. Ontarion Confederation of University Faculty Associations [Online] Available: www.ocufa.on.ca/OCUFA/docs/policies 3 October 2009. [Accessed: 23 March 2011].

Redmond, C. 2008. Lessons Learned from Satellite Campuses [Online]. University of Waterloo Daily Bulletin. Available http://www.bulletin.uwaterloo.ca/2008/oct/29we.html [Accessed 28 January 2010].

Reisz, M. 2010. Maintaining Orbit in Hostile Skies [Online]. The Times Higher Education, 13 May 2010. Available: htwww.timeshighereducation.co.uk/story.asp?sectioncode=26\&storycode=411551 [Accessed 28 March 2011].

Scott, G.; Bell, S.; Coates, H. \& Grebennikov, L. 2010. Australian higher education leaders in times of change: the role of Pro ViceChancellor and Deputy Vice-Chancellor [Online]. Journal of Higher Education Policy and Management, Vol.32, No.4 August 2010, 401-418. Available: http://www.informaworld.com [Accessed: 24 October 2011].

Serfontein, J.J. 2010. The impact of strategic leadership on the operational strategy and performance on business organisations in South Africa. Doctor of Philosophy (PhD) Thesis [Online]. Available: scholar.sun.ac.za/.../serfontein_impact_2010.pdf [Accessed: 30 March 2013]. 
Singh, A. \& Khanna, V.S. 2010. Thinking beyond foreign university branch campuses: the Fore (Regulation of Entry and Operations) Bill 2010 [Online]. Available: http://www.criticaltwenties.in/lawthejudiciary/thinking-beyond-foreign-university-branch [Accessed: 8 September 2011].

Skodvin, O. 1999. Mergers in higher education - success or failure? Tertiary Education and Management, 5:1, $65-80$ [Online]. Available: http://dx.doi.org/10.1080/13583883.1999.9966981 [Accessed: 23 January 2012].

Soy, S.K. 1997. The case study as a research method [Online] Available: http://www.ischool,utexas.edu/ ssoy/usesusers/1391dlb.htm [Accessed: 11 September 2011].

Stringer, B., \& Hudson, P. 2008. Sustaining educational futures for multi-campus TAFE environments: Change requirements for leadership roles and practices. Proceedings of the Association for Active Educational Researchers (AARE) International Educational Research Conference. Brisbane: AARE [Online]. Available: www.herdsa.org.au/wp-content/uploads/.../HERDSA 2010_Ebden_M.pdf [Accessed: 4 May 2013].

Teferra, D. \& Altbach, P.G. 2004. African higher education: challenges for the $21^{\text {st }}$ century [Online]. Higher Education Vol. 47 , No. 1 January 2004 pp 21-50. Available: http://www.jstor.org/stable/4151555pdf [Accessed: 19 June 2011].

Timberlake, G.R. 2004. Decision-making in multi-campus higher education institutions, The Community College Enterprise, Fall 2004, 91-99 [Online]. Available: classnotes-org-gov.mwmwikis.net/pdf [Accessed: 4 April 2013.

Viljoen, J.P. \& Rothmann, S. 2002. Transformation in a tertiary-education institution: A case study [Online]. Management Dynamics Vol. 11, No.2 2002. Available: www.cept.org.za/files [Accessed: 10 January 2011]. 